\title{
Transfer of climate knowledge via a regional climate-change management body to support vulnerability, impact assessments and adaptation measures
}

\author{
Luc Vescovi ${ }^{1,2, *}$, Alain Bourque ${ }^{1}$, Guillaume Simonet ${ }^{1}$, André Musy ${ }^{1}$ \\ ${ }^{1}$ Ouranos - consortium sur les changements climatiques, 550 Sherbrooke Ouest, Tour ouest, 19ième étage, Montréal, \\ Québec H3A 1B9, Canada \\ ${ }^{2}$ Present address: Conseil de la science et de la technologie, 2021 Avenue Union, Bureau 935, 9e étage, Montréal, \\ Québec H3A 2S9, Canada
}

\begin{abstract}
We provide an overview of how climate-change-science knowledge transfer is achieved at Ouranos in support of vulnerability and impact assessments and adaptation (V\&I\&A) activities. Ouranos is a Canadian consortium concerned with regional climatology and adaptation to climate change, launched in 2002 by the Government of Québec, Hydro-Québec and the Meteorological Service of Canada to coordinate climate-change research in Québec. Focusing on Ouranos' ongoing V\&I\&A projects in coastal regions, we describe the current knowledge-transfer environment. We also discuss how climate indices and indicators of vulnerability - which are developed by Ouranos following a 'pressure-state-response' (PSR) framework-form useful knowledge-transfer tools. Two specific case studies exemplify the development of (1) a set of temperature-trend indices for southern Québec and (2) climate-social indicators for the assessment of risks to public health due to extremely high temperature events. Case Study (1) illustrates how a systematic analysis of climate variability and relevant indices of extremes can be useful for decision makers at regional scales (southern Québec). Case Study (2) examines the potential, and feasibility, of using a risk-assessment framework for regional climate-change studies that focus on impacts and adaptation.
\end{abstract}

KEY WORDS: Regional climate change $\cdot$ Climate vulnerability $\cdot$ Indicators $\cdot$ Impacts and adaptation

\section{INTRODUCTION}

Reducing the adverse impacts of climate change requires both mitigation and adaptation efforts. Indeed, even if $\mathrm{CO}_{2}$ emissions stabilized at Kyoto levels, the planet would experience warming for the next $100 \mathrm{yr}$ (IPCC 2007) and require the implementation of adaptive measures. Adger et al. (2004) show how climate adaptation policy involves estimation of both physical (from data and scenarios at both global and local scales) and social vulnerability (from adaptive capacity based on socio-economic indicators).

Adaptation to climate change is a wide-ranging and complex issue involving numerous technical and scientific challenges, and requiring effective communica- tion and knowledge transfer between researchers and decision makers. This knowledge transfer is needed to address issues such as the compatibility of spatial and temporal scales, multidisciplinary and integrated approaches, language used by researchers in relation to users of study results, management and integration of uncertainties, etc. Climate adaptation policy requires the establishment of timescale and planning horizons. Recently, according to the IPCC 4th Assessment Report (IPCC 2007), numerous long-term changes in climate trends have been observed not only at continental, but also at regional and ocean-basin scales. These include changes in annual and seasonal Arctic temperatures and ice cover, widespread changes in precipitation amounts, levels of ocean salinity, wind pat- 
terns and extreme weather events including droughts, heavy precipitation, heat waves and increased intensity of tropical cyclones. Thus, actions taken to increase regional and institutional adaptation should be anticipatory, and be planned so as to minimize costs and optimize opportunities. The challenge is how to tackle climate change at the regional level while at the same time reconciling scientific and management concerns, and thus integrating theory and practice.

With the aim of addressing these issues, Ouranos was founded in 2001 thanks to the initiative and participation of the Québec government, the Crown Corporation Hydro-Québec and Environment Canada (with the financial support of Valorisation-RechercheQuébec). Four universities, already involved at a scientific level, officially joined this initiative in 2004, namely the Université du Québec à Montréal (UQAM), McGill University, Université Laval, and the Institut national de la recherche scientifique (INRS). More recently, École de technologie supérieure (ÉTS), the Crown Corporation Manitoba Hydro, Université du Québec à Rimouski (UQAR) as well as the Crown Corporation Ontario Power generation (OPG) joined the consortium as affiliated members. The first phase of Ouranos (2001-2005) concluded with the establishment of a flexible organisation with facilities, computer resources, financial and human resource contributions from its members (www.ouranos.ca/), a scientific program and a knowledge base of current thinking on climate-change adaptation (Ouranos 2004, Lemmen et al. 2008). Seen as a critical mass of expertise on applied climate change science, connecting around 250 scientists and professionals, Ouranos' mission is to acquire and develop knowledge on climate change (as well as on its impact and related socioeconomic and environmental vulnerabilities) in order to inform its members (mainly Québec governmental decision makers) about probable climate trends, and to advise them in the formulation, assessment, promotion and implemention of local and regional adaptation strategies.
This unavoidably involves developing structures for analysis of multidisciplinary problems (illustrated in Fig. 1), promoting synergetic work and developing or optimally applying tools like the Canadian Regional Climate Model (CRCM; Plummer et al. 2006) or climate and socio-economic scenarios, required to support vulnerability and impact assessments and develop adaptation strategies (V\&I\&A).

As illustrated in Fig. 2, Ouranos's scientific programme is structured around several major programmes: (1) arctic populations and ecosystems, (2) northern resources, (3) public safety and secure infrastructures, (4) energy supply, (5) water resources, (6) health, (7) maritime environment and coastal erosion, (8) forestry, agricultural, mining, tourism and transportation operations, (9) protecting the natural environment. These programmes address local issues and answer to the needs expressed by Ouranos members and government departments and institutions in Québec, as well as in other parts of Canada.

By enabling direct links among climate scientist and experts developing V\&I\&A activities, Ouranos provides/ creates opportunities for innovative dialogue and facilitates knowledge transfer. To illustrate this, below are presented (1) the structure of a coastal region V\&I\&A project and (2) 2 case studies discussing the use of indicators as a potential knowledge translation tool from science to environmental management practices.

\section{KNOWLEDGE TRANSFER FROM SCIENCE TO PRACTICE: THE OURANOS APPROACH}

One of the greatest challenges regarding knowledge transfer is the issue of uncertainty. One approach to cope with the uncertainties regarding future impacts of climate change to human and natural systems is the use of climate scenarios (as one component within a combination of decision-support tools). These representations of plausible future climates can help with

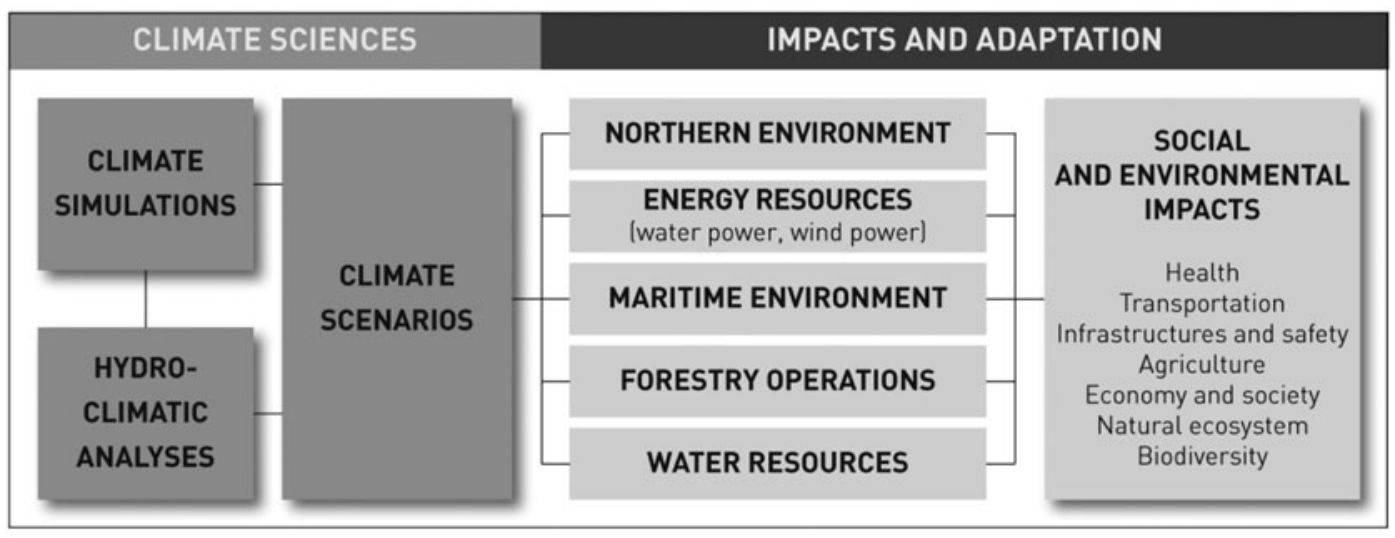

Fig. 1. Ouranos: scientific programs 


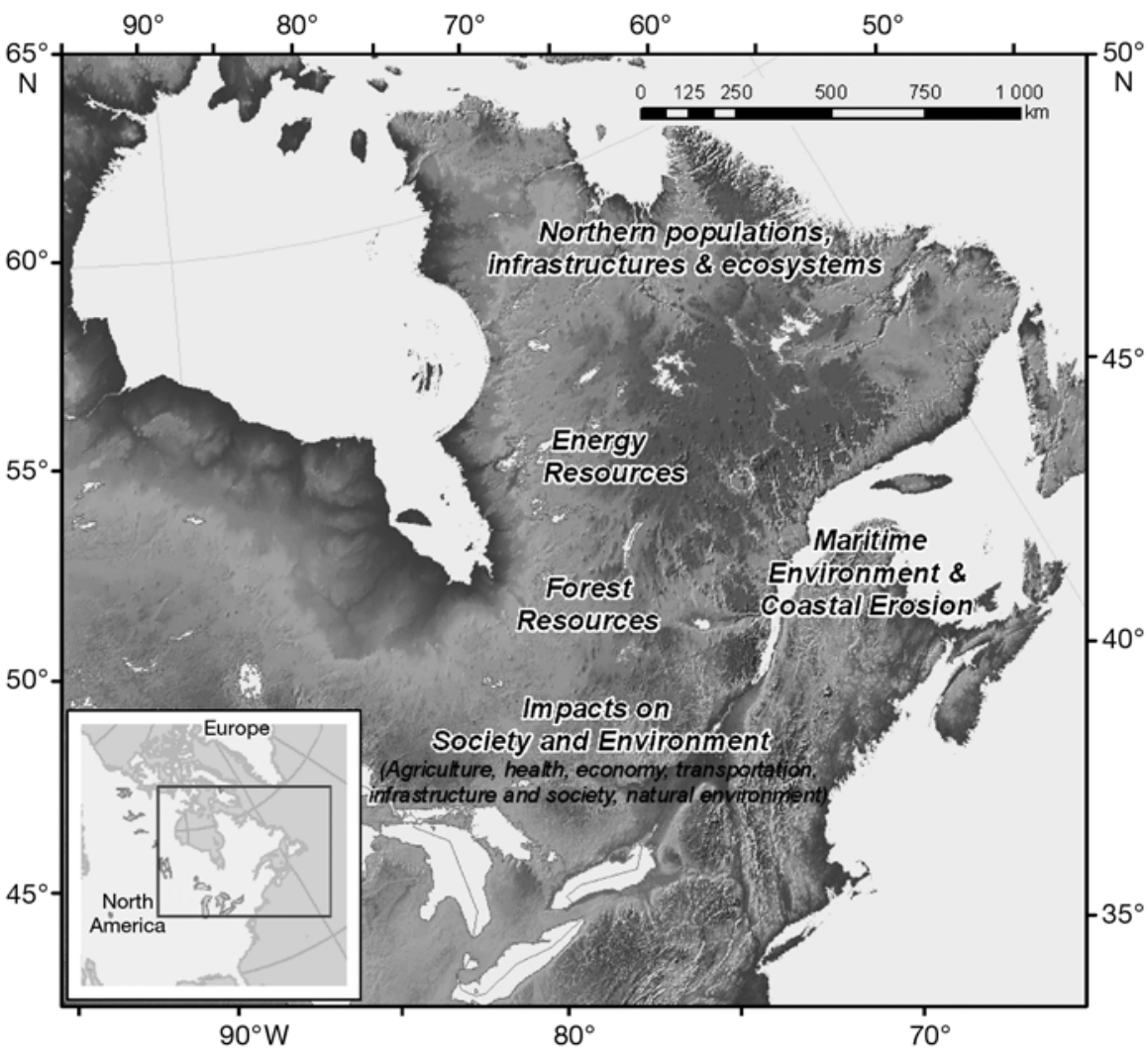

Fig. 2. Ouranos: geographical coverage

used to develop climate adaptation policies that enhance coping capacity for both human and natural environments (Adger et al. 2005). In its programs, Ouranos has several projects that combine top-down and bottom-up approaches. In all cases, the organisation's structure and the projects Ouranos coordinates allow a 2-way transfer of information, data, results, priorities and research questions between climate specialists, impact and adaptation researchers and user-groups to ensure the evaluation of potential impacts that are most relevant to the interest groups, and to facilitate mainstreaming of adaptation solutions both during and after projects. Right from the start of a project, brainstorming sessions bringing together researchers and concerned institutions help to define the scientific and management issues involved with climate-change adaptation, thus leading to integrated research projects. The projects are designed to combine the development of regional climate projections, the assessment of physical and

the formation of climate adaptation policies by allowing estimation of potential consequences of anthropogenic climate change (Larrivée \& Simonet 2008). This approach, often called the 'top-down' approach, stems from research and development in climate scenarios. Models are then typically used to evaluate impacts and extrapolated to eventually estimate physical vulnerabilities at local levels (Dessai \& Hulme 2004). However, there are significant challenges associated with this approach, in particular regarding the accumulation of uncertainties, the possibility of nonlinear responses to very high greenhouse gas concentrations (IPCC 2007), the difficulty of estimating economic and social costs or vulnerabilities (Ambrosi \& Courtois 2004) and the potential lack of participation of the user-groups. This is why several authors focus on user-driven research and non-climatic factors, which can have great influence at regional scales when added to climate change effects (Kelly \& Adger 2000). Thus, in order to either build-at the local level-a strong adaptive capacity (or determinants thereof), or estimate existing or future adaptive capacity, developers of adaptation policy require data from indicators based on socio-economic components of the studied system (Yohe 2000). This 'bottom-up' approach is based on short temporal and local scales and can be human impacts related to climate change and adaptation measures appropriate to stakeholders and interest groups involved with Ouranos.

Of its various programs, the project addressing coastal erosion has been one of the most successful. Fig. 3 illustrates the framework of this project located along the coastlines of the Gulf of St. Lawrence in eastern Québec. Bridging the gaps between the scientist, the administration and local stakeholders (e.g. municipalities etc.), the project is led by a public safety official who devotes part of his time to the Ouranos consortium. This official is in charge of a Québec government program on natural hazard risk reduction, and the incumbent official is well-known for his leadership and his interests in integration, crisis situation management and participatory approaches, as well as for his knowledge of local-scale human and physical geography and his communication skills. The project includes a 'climate' group, a 'vulnerability' group and an 'adaptation and users' group working in parallel and who have agreed on the research questions to be addressed and on the added-value tools and scientific information to be developed. Three-way communication is ensured through a variety of means, such as face-to-face meetings, brainstorming sessions, surveys, forums and symposiums that take place throughout the project stages 
(from the definition of the project to its conclusion). In this context, Ouranos can be considered as a boundary organisation (Cash et al. 2003), targeting the salience, credibility and legitimacy of the information. Also, by fostering active, horizontal and vertical multidirectional communication (between experts and decision makers), making use of both translation (to insure participants understand each other) and mediation (through the establishment of rules of conduct during the project), it is ensuring an efficient management of the information between all participants. From the onset, it was established that adaptation is occurring in a complex world and for a number of reasons: the need to deal with a variable and changing climate (rather than a variable and stable climate), a multi-stakeholder environment, various spatial and temporal scales of interest, various levels of jurisdictions, cross-disciplinary information, and innovation and efficient knowledge transfer. The project structure helps take these things into account, maximizing communication while developing tools as presented in Fig. 4.

The climate group develops or applies tools such as the CRCM, climate scenarios and historical data trend analyses, to assess past measures and future probabilistic evolutions of 4 climatic indices (ice cover, detailed in Senneville \& Saucier 2007; freeze-thaw cycles, detailed in Bernatchez et al. 2008; storminess, summarized in Savard et al. 2008; and water levels, detailed in $\mathrm{Xu}$ et al. 2006) that have been identified by the coastal dynamics researchers and local experts as relevant for coastal erosion processes. The coastal dynamics group initially used historical trends in coastal erosion, and used expert judgment to propose optimistic, average and pessimistic erosion scenarios for the next $30 \mathrm{yr}$ for 3 pilot areas (a few kilometres of coastline selected by 3 communities) (Bernatchez et al. 2008). This group then used, for example, outputs from the climate, adaptation and users groups and from their own sectorial research to better assess the probable evolution of biophysical vulnerability of the selected coastline. Although Ouranos eventually plans to develop and use a fully probabilistic approach, the tools and results generated by this project are considered to better orient expert opinions, which are focussing their effort on establishing which of the 3 coastal erosion hypotheses identified above are more likely within the next 30 to $50 \mathrm{yr}$. The adaptation and user group reassesses potential impacts of the different coastal erosion scenarios and discusses adaptive capacity or even mandate-specific adaptation option studies with the objective of revisiting current practices in coastal zone management. One advantage of this project structure is the availability of simple indices or indicators, facilitating knowledge transfer. The project enhances adaptive capacity through, for example, renewed land management rules at the provincial and municipal level (Mehdi et al. 2005) and provides a detailed cost-benefit analysis of various

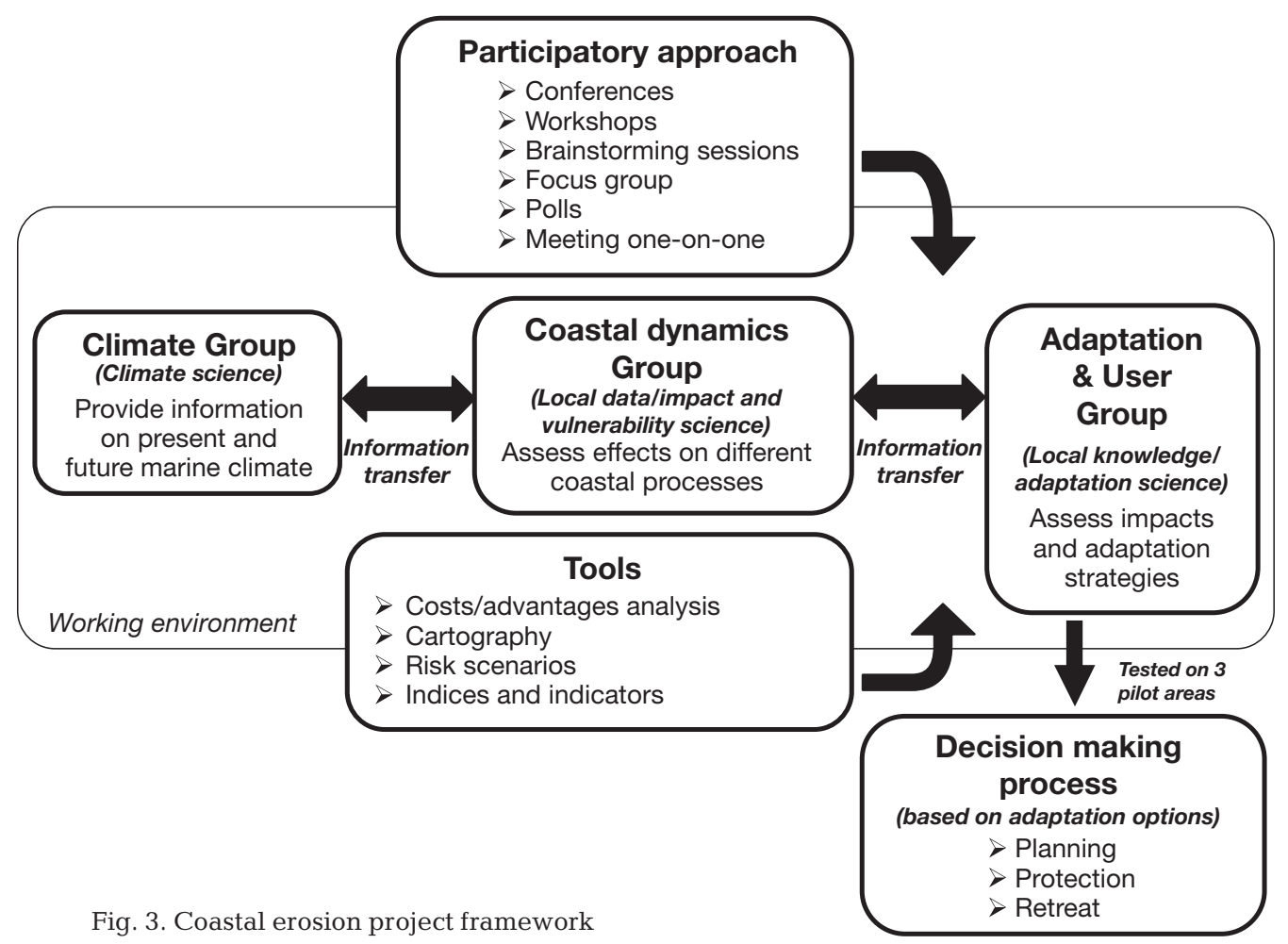




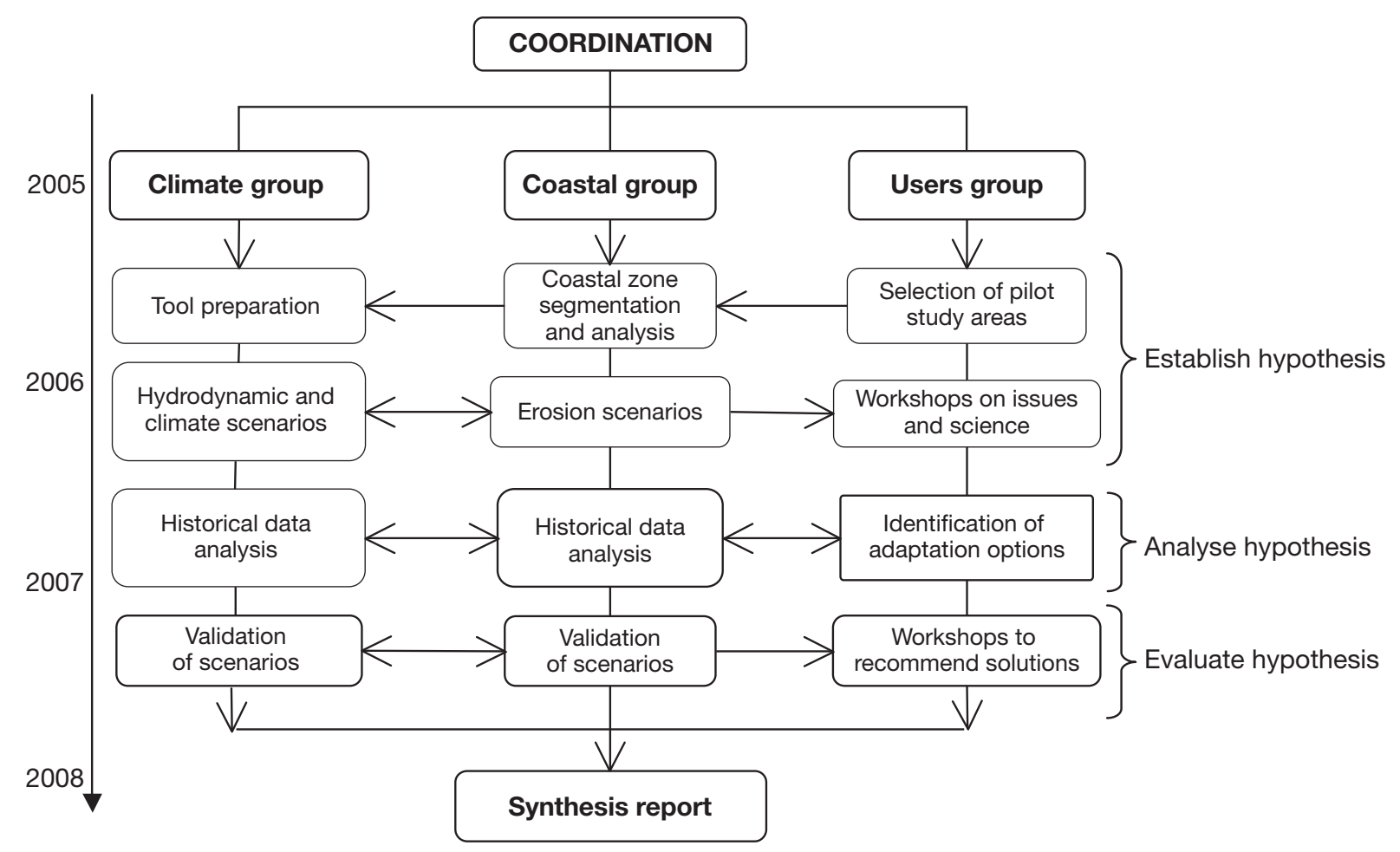

Fig. 4. Coastal erosion project strategy and structure (arrows: key interactions between collaborators at various stages of the project). Source: Savard \& Bourque (2008)

adaptation solutions for a specific community (Tecsult 2008); and agreement in a number of cases on optimal adaptation solutions (Savard et al. 2008).

\section{INDICATORS AS A KNOWLEDGE TRANSLATION TOOL}

This section discusses the development and use of indicators as an interface and knowledge translation tool by Ouranos. This is illustrated by a more detailed look at 2 specific case studies addressing (1) the development of a set of temperature trend indices for southern Québec, and (2) climate and social indicators assessing public health risks due to extremely high temperature events. The 2 case studies serve to illustrate how indicators have been developed by Ouranos following a 'pressure-state-response' (PSR) framework and suggest what the future development for this could be. The PSR framework states that human activities exert pressures (e.g. pollution emissions) on the environment that can induce changes in the state of the environment (e.g. changes in ambient pollutant levels, climate characteristics, water flows, etc.). Society then responds to changes in pressure or state with environmental and economic policies and programs intended to adapt, prevent, reduce or mitigate these pressures and/or environmental damages.

\subsection{Case study 1: development of climate indices for southern Québec}

A recent study of Canada's climate shows significant changes in temperature and precipitation occurring during the twentieth century (Vincent \& Mekis 2006). However, because the climate indices used reveal a high degree of spatial variability, Vincent \& Mekis (2006) conclude that more detailed research is needed on a regional basis. In 2002, Ouranos launched a historical data study (in collaboration with the Québec Ministry of Sustainable Development, Environment and Parks), to examine regional temperature trends across southern Québec (Yagouti et al. 2008). Consequently, 1960 to 2003 daily minimum and maximum recorded temperature series at 53 stations were analysed and homogenised. Homogeneity problems, due to station relocations and changes in observation procedures, were addressed using a technique based on regression models and surrounding stations (Vincent 1998). The technique used to identify inconsistencies/ incongruities was tailored to the regional Québec data set used (Yagouti et al. 2008). Thus, 106 maximum and minimum temperature (Tmax and Tmin) series were homogenized on various temporal scales (daily, monthly, seasonal and annual). The results of the homogenisation process show that only $36 \%$ of the 106 series were homogeneous. Amplitudes of the detected inconsisten- 
cies were estimated and corrections were made where necessary to the non-homogeneous series. At the end of the process, 52 statistically homogeneous stations were retained. One station was eliminated because of the high percentage of missing values and the many relocations of this station during the time period.

The temperature indices computed from these homogenized series were calculated in close collaboration with Ouranos' stakeholders, with the aim of providing a broad overview of the southern Québec climate. The results show that the surface air temperature has increased in southern Québec over the period 19602005. The warming is more pronounced in the western, southern and central parts of the province and the increasing trends become smaller toward the east. Significant annual mean temperature trends range from 0.6 to $1.8^{\circ} \mathrm{C}$ for $1960-2005$. The warming is more evident during the winter, although several significant increasing trends were also found during the summer. The warming is slightly more pronounced in nighttime than in daytime temperature. The temperature indices also suggest a decrease in the length of the frost season (number of consecutive days starting when mean temperature [Tmean] $<0^{\circ} \mathrm{C}$ for at least 6 consecutive days and ending when Tmean $>0^{\circ} \mathrm{C}$ for at least 6 consecutive days, July to June) (Fig. 5a) and an increase in the length of the growing season (number of consecutive days starting when Tmean $>5^{\circ} \mathrm{C}$ for at least 6 consecutive days and ending when Tmean $<5^{\circ} \mathrm{C}$ for at least 6 consecutive days, January to December) (Fig. 5b), an increase in cooling degree days (sum of degrees when Tmean $>22^{\circ} \mathrm{C}$ ) (Fig. 5c) and a decrease in heating degree days (sum of degrees when Tmean $<18^{\circ} \mathrm{C}$ ) (Fig. 5d) as well as an increase in the number of freeze-thaw cycles during the winter (Fig. 5e) and a decrease in the number of freeze-thaw cycles during the spring (Fig. 5f). Case study 1 improves our understanding of the trends and variations in temperature and precipitation indices in Southern Québec. The majority of the findings are consistent with those expected in a warmer climate. The observed warming appears to have some beneficial impacts for certain socio-economic activities in Québec, such as a longer growing season and a shorter frost season. However, the warming can also have adverse effects on various industries in Québec, including a shorter tourism season in the winter and increased energy demand for cooling buildings in the summer.

\subsection{Case study 2 : indicators of risk to public health from high-temperature events}

Vescovi et al. (2005) demonstrate the feasibility and potential of a risk-assessment approach, as well as describing the development of public health risk indices for a regional impact and adaptation climate-change study applied to heat waves in southern Québec. The methodology developed for this study was inspired by the NOAA Coastal Services Center (1999) vulnerability assessment tutorial, by the EPA (1998) guidelines for Ecological Risk Assessment, by Cutter \& Scott et al. (1997) and Schiegg (2000), and by the Tyndall Centre's research studies (Adger et al. 2004). Climate variables and socio-economic parameters were integrated via a geographic information system (GIS) tool to produce maps of estimated present and future public health risks.

To characterize current climate hazards, data from 310 Environment Canada stations in southern Québec were used along with 2 indices:

(1) Mean number of days with $\operatorname{Tmax}>30^{\circ} \mathrm{C}$, for weather stations with data for $\geq 16$ years between 1971 and 2000 (272 stations) (Fig. 6a). This index was interpolated using the natural neighbor method.

(2) Mean number of episodes per year with $\geq 3$ consecutive days having $\operatorname{Tmax}>30^{\circ} \mathrm{C}$ and $\operatorname{Tmin}>22^{\circ} \mathrm{C}$ (see red dots in Fig. 6a). These were computed from daily temperature series within the period 1971-2000 for stations with values $>2.5 \mathrm{~d} \mathrm{yr}^{-1}$ for Index (1) (67 stations).

These indices are based on practical characterizations of extreme temperature events established by the Montreal Public Health Board, which recently proposed using an operational definition of 'extreme high temperature' that was based on a daytime high of $30^{\circ} \mathrm{C}$ (Tmax) and nighttime low of $22^{\circ} \mathrm{C}$ (Tmin) for 3 consecutive days (Drouin et al. 2005).

To characterize future climate hazards related to potential impacts of extreme heat, climate projections for 2039-2063 were calculated using the CRCM V3.6.1, driven by the coupled ocean-atmosphere model CGCMII, and following the IS92a (IPCC) emissions scenario for greenhouse gas emissions (see Fig. 6b). The CRCM performs climatic simulations at a small-scale resolution (distance between each grid point about $45 \mathrm{~km}$ ) and for time steps of $15 \mathrm{~min}$. At the time of this experiment (2004), a single CRCM run projection using IPCC IS92 emission scenario was available (horizon 2039-2063). Today, in accordance with the latest IPCC standards, multiple CRCM runs using SRES a2 emission scenarios for the period 1961-2100 are available, and thus to address climate change projection uncertainties and climate stochasticity, the approach at Ouranos is to provide V\&I\&A experts with scenarios based on an ensemble of simulations.

Social vulnerability was calculated for Québec through 4 social sub-indices; this data was considered relevant elsewhere for defining vulnerability to extreme high temperature events (see Fig. 6c; Vescovi et al. 2005). These 4 sub-indices are: 

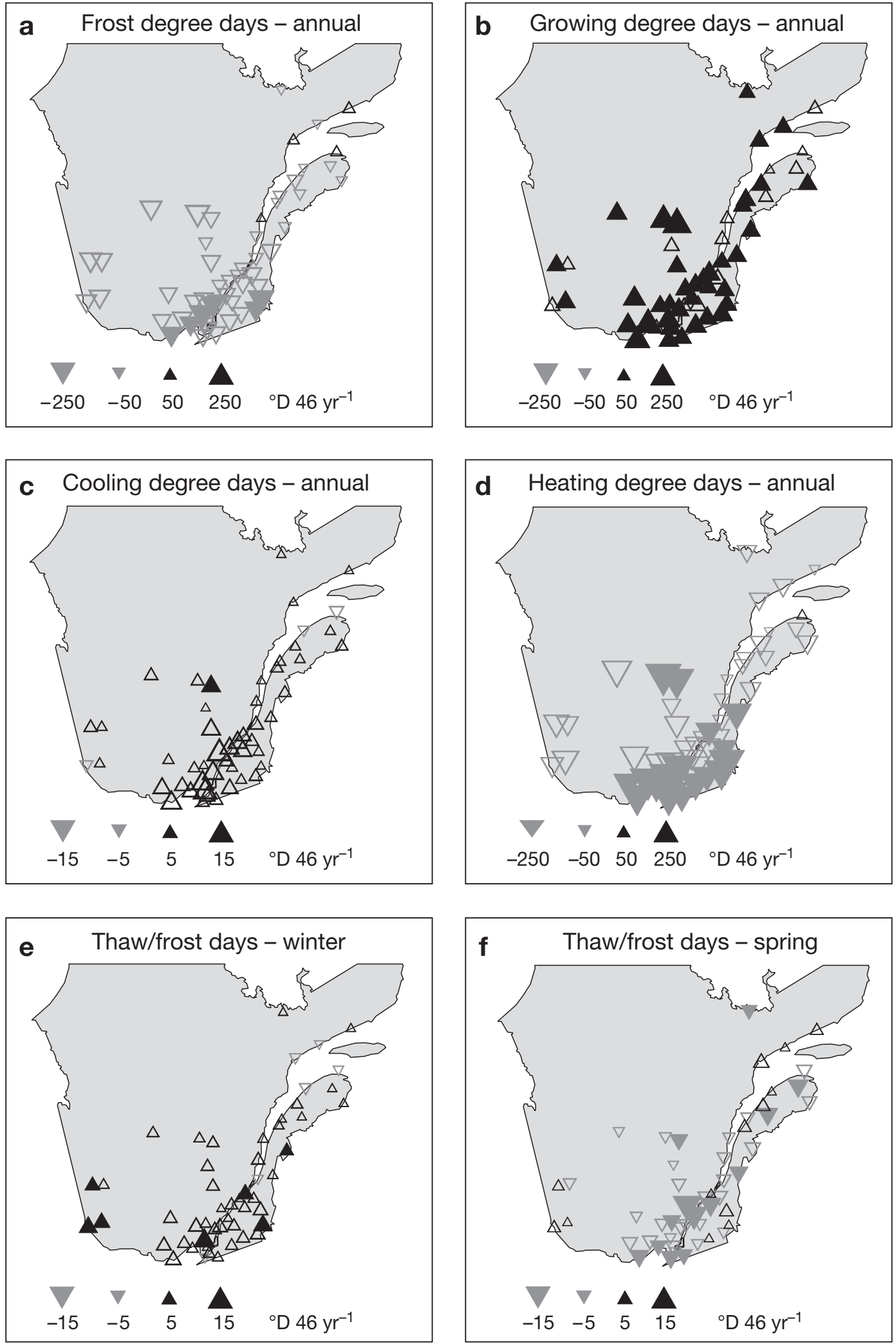

Fig. 5. Trends in 6 temperature indices for 1960-2005. Upwards, downwards pointing triangles: positive and negative trends, respectively (the size of the triangle is proportional to the magnitude of the trend); filled symbols: trends with $\mathrm{p}<0.05{ }^{\circ} \mathrm{D}$ : degree day. From Yagouti et al. (2008) 


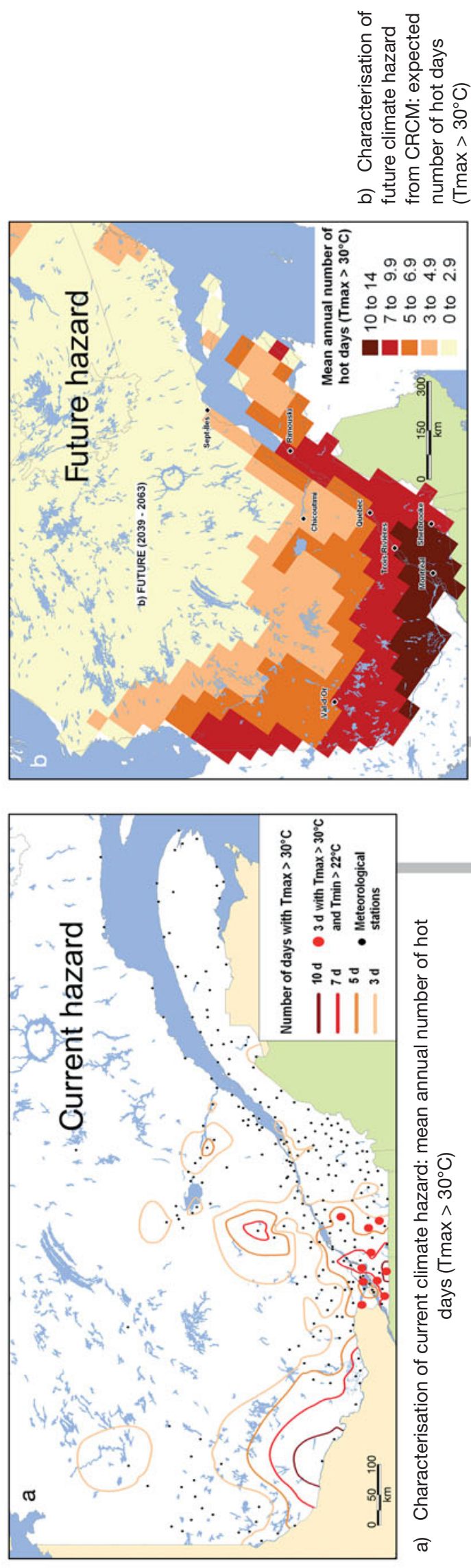

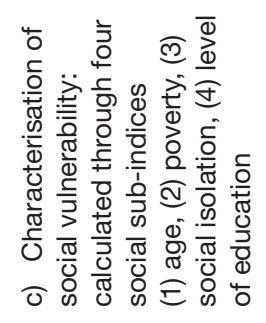
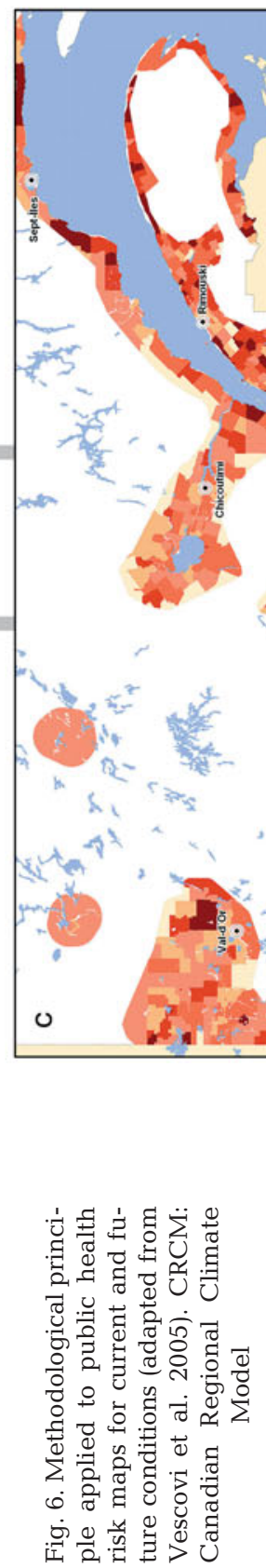
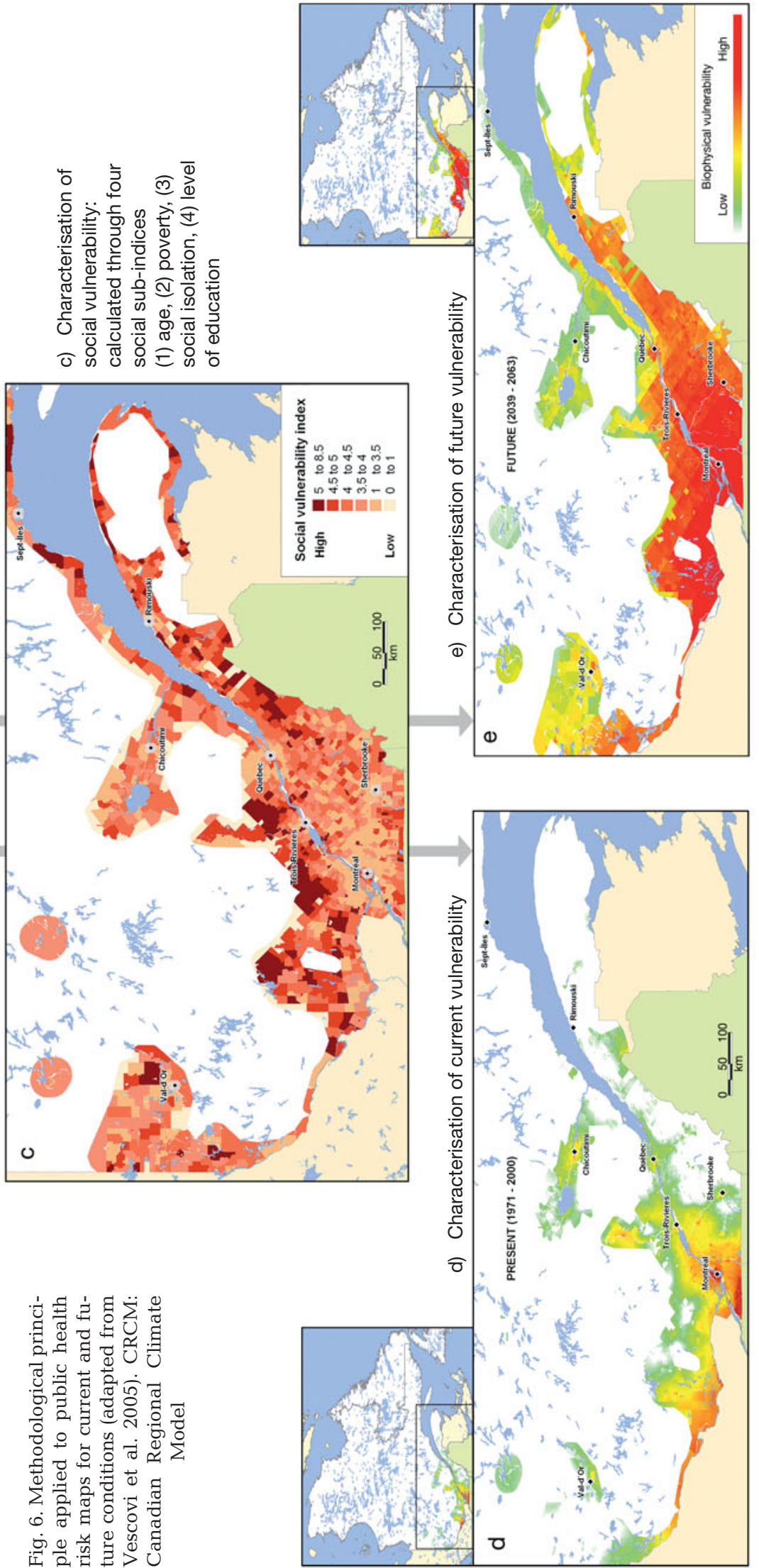
(1) Age index: frequency of people aged 65 and over

(2) Poverty index: frequency of low-income earners (LICO) by Statistics Canada for rural zones, with the FGT (Foster-Greer-Thorbecke) index by classes of income in 2000 Canadian dollars

(3) Social isolation index: frequency of single person households

(4) Education index: frequency of people aged 20 and over with $<13$ yr of education

A comparison of risk maps for present and future conditions (Fig. 6d,e) showed that the number of locations where populations would be at risk due to high temperature events would dramatically increase in Québec over the next few decades. Based upon the assessment of biophysical vulnerability (a concept that combines physical and human processes; see Füssel 2007) to climate change, this study gives preliminary input for the Québec public health decision-makers currently developing a spatially explicit on-line analytical processing tool using Web-GIS technology to identify areas potentially vulnerable to climate change.

\section{DISCUSSION AND CONCLUSIONS}

By creating Ouranos, Canadian decision makers at the national and provincial levels confirmed that V\&I\&A, in the context of climate change, is a priority. More than simply supporting an integrated scientific program, one additional objective is to develop a structure for analysis of multidisciplinary problems and to promote synergetic work in the search for solutions to climate change adaptation issues in a North American context. By working at a regional scale and enabling links between various researchers and decision-makers, Ouranos, an example of a 'boundary organisation' (Cash et al. 2003), provides an opportunity for innovative multidisciplinary, multiorganisational dialogue and facilitates the mainstreaming of adaptation. Various methodologies are used by the 'scientific brokers' of Ouranos to accomplish this, including face to face meetings, brainstorming sessions, surveys, forums, symposiums and scientific projects which ideally include a climate, a vulnerability and an adaptation component working in parallel to achieve the project objectives. Also, Ouranos develops or tailors different tools to support V\&I\&A analyses, e.g. the CRCM and climate change scenarios applied for priority issues. Using concrete examples taken from Ouranos' ongoing V\&I\&A projects in coastal regions, this study demonstrates Ouranos' support of the process from scientific research (some of which is carried out at Ouranos) through the transfer of this knowledge, to practical applications.
Among the knowledge transfer tools available, the development of climate indices and indicators of vulnerability is now recognised as being very useful for assessing positive and negative impacts to global and regional climate change. The assessment of trends, processes and warning signals (e.g. extreme temperature events, precipitation events, sea level rise, etc.) and the reporting of the efficiency of adaptation strategies tend to lead to the development of indicators. In each case, the strength of the metric will be its diagnostic value in attributing detectable changes to identifiable forcing factors. Also, credible vulnerability indicators for climate adaptation policy assessment that can effectively aid policy development will be developed only if the causes of climate changes vulnerabilities are better understood (Eriksen \& Kelly 2007). Another major challenge is to adequately address long-term climate change trends with short-term managerial commitments (Corfee-Morlot \& Höhne 2003). In that sense the PSR framework developed by the Organisation for Economic Cooperation and Development (OECD 1993, 2006) is well suited to the climate change context, since it is designed to increase the ability of decision makers to cope with and manage a changing system. The framework is continuing to evolve and, as stated by Füssel (2007), is one of a number of tools available to pragmatically assess climatechange vulnerability and adaptation policies. It should be noted that in the climate-change context, it is important to clearly differentiate between pressure and state indicators. Indeed, when one is looking at the climate system, greenhouse-gas (GHG) increase is the pressure factor raising global temperature and affecting precipitation patterns, causing environmental problems. Conversely, when one is looking at the natural and/or human systems, climatic changes are the driving factors causing environmental impacts and affecting human responses to adapt to a novel situation. Therefore, the PSR framework needs to be expanded to deal more specifically with anthropogenic climate change trends, their impacts, and adaptation measures. One way to get around the problem is by distinguishing driving forces on the one hand and impacts on the other. This has broadened the scope of the PSR model giving the driving force-state-response (DSR) framework selected by the United Nations Commission on Sustainable Development (www.un.org/ esa/sustdev/isd.htm) and the driving the driving forcepressure-state-impact-response (DPSIR) framework (EEA 1999). Furthermore, Holman et al. (2008) discuss how the setting of indicators following a DPSIR framework is a basis for regional climate-change assessment. In this case, the outcome of the study is the development of sophisticated user-interface software helping stakeholders to cope with regional climate- 
change issues. More recently, Niemeijer \& de Groot (2008) proposed an enhanced and more sophisticated DPSIR (eDPSIR) framework to tackle the complexities of the real world by looking at causal networks in which multiple causal chains interact and inter-connect.

Even though our objective is not as ambitious to the degree of developing a sophisticated user-interface software and framework, we believe that climate indices and indicators of vulnerability (specific and relevant to each of the issues and regions of interest identified by Ouranos) following a PSR framework are useful knowledge transfer tools, and the use of these provides an effective regional climate change assessment methodology for Québec. Due to the very high level of complexity and uncertainty (e.g. due to climate models and scenarios) we suggest (from our experience) that another way to look at the question of indicators in a climate-change context is to keep the set of indicators as simple as possible and to tailor the PSR framework for specific managerial issues, thus looking at a context specifically relevant to stakeholders. We propose a PSR grouping of indices and indicators of climate-change vulnerability, distinguishing climate and natural and human systems, as illustrated in Fig. 7. It should be seen as the first step of a work-in-progress that, may be a useful reference for additional work at the provincial level (within Ouranos) on linking climate change policy and sustainable development through the use of indicators. In that sense it follows the rationale of the UN Expert Group on Climate Change and Sustainable Development assessing the role of indicators in measuring progress towards sustainable development and climate change (United Nations Division for Sustainable Development 2008).

\section{LITERATURE CITED}

Adger NW, Kelly M, Bentham S, Eriksen S (2004) New indicators of vulnerability and adaptive capacity. Report No. 7, Tyndall Center for Climate Change Research, Norwich

Adger NW, Arnell NW, Tompkins EL (2005) Successful adaptation to climate change across scales. Glob Environ Change 15:77-86

Ambrosi P, Courtois P (2004) Impacts du changement climatique et modélisation intégrée, la part de l'arbitraire. Nat Sci Soc 12:375-386

Bernatchez P, Fraser C, Friesinger S, Jolivet Y, Dugas S, Drejza S, Morissette A (2008). Sensibilité des côtes et vulnérabilité des communautés du golfe du Saint-Laurent

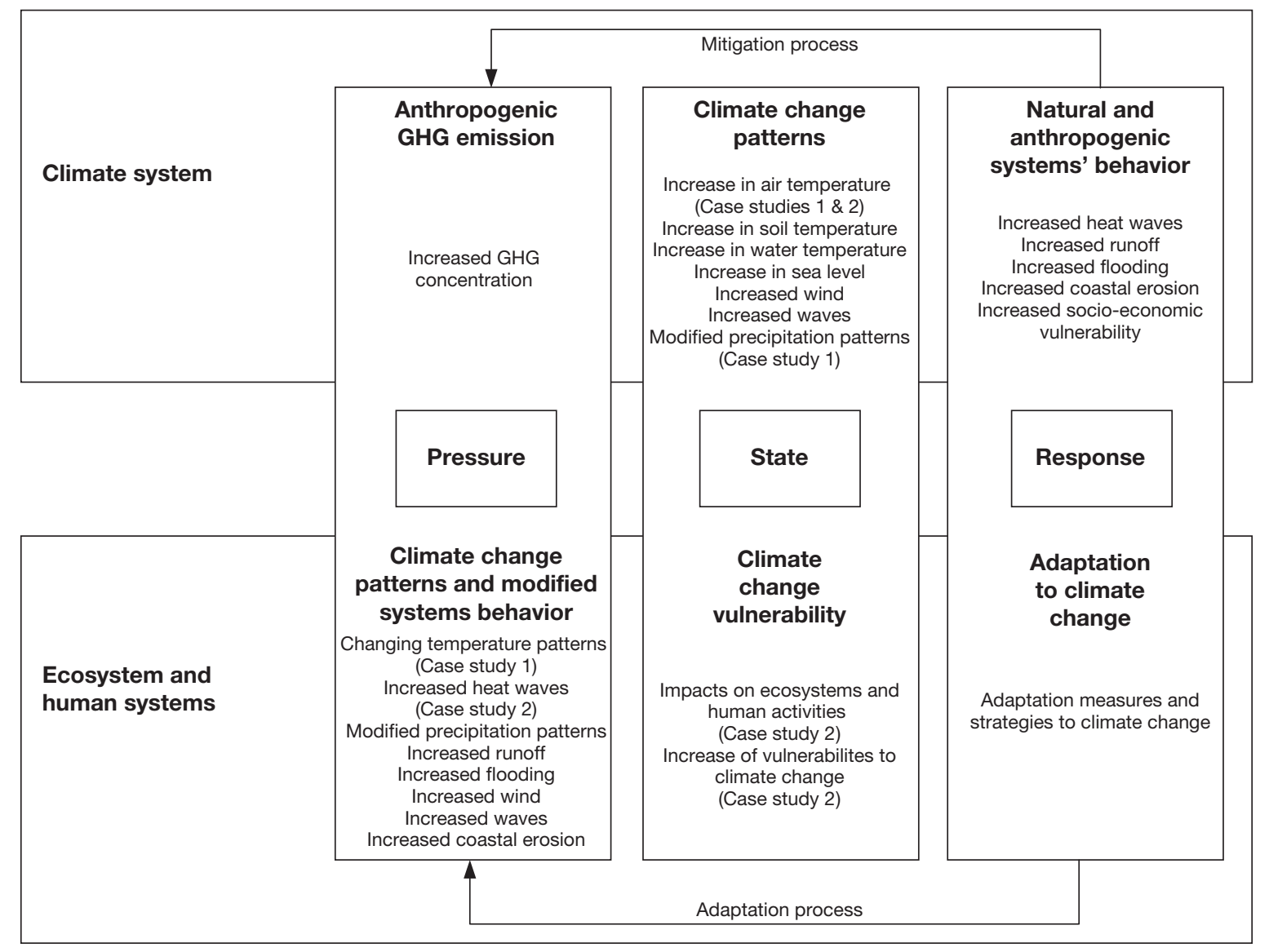

Fig. 7. Matrix grouping indicators according to the PSR approach. GHG: greenhouse gas 
aux impacts des changements climatiques. Rapport de recherche remis au Consortium Ouranos et au FACC, Université du Québec à Rimouski, Laboratoire de dynamique et de gestion intégrée des zones côtières, Rimouski

Cash DW, Clark WC, Alcock F, Dickson NM and others (2003) Knowledge systems for sustainable development. Proc Natl Acad Sci USA 100:8086-8091

Corfee-Morlot J, Höhne N (2003) Climate change: long term targets and short term commitments. Glob Environ Change 13:277-293

Cutter S, Scott SM (1997) Handbook for conducting a GISbased hazard assessment at the county level. University of South Carolina, Columbia

Dessai S, Hulme M (2004) Does climate adaptation policy need probabilities? Clim Policy 4:107-128

Drouin L, King N, Jacques L, Fortier I and others (2005) The response of the Montreal public health board to climate change: preventing excess morbidity and mortality due to extreme summer temperatures in vulnerable human populations. Proc 'Adapting to climate change in Canada 2005: understanding risks and building capacity', 4 to 7 May 2005, Montreal, Québec (www.adaptation2005.ca/ abstracts/pdf/drouin_lisa.pdf)

EEA (1999) Environmental indicators: typology and overview. Tech. Rep. n.25, European Environmental Agency, Copenhagen (http://reports.eea.europa.eu/TEC25/en, accessed August 2004)

EPA (1998) Guidelines for ecological risk assessment. US Environmental Protection Agency, Risk Assessment Forum, Washington DC

Eriksen SH, Kelly PM (2007) Developing credible vulnerability indicators for climate adaptation policy assessment. Mitig Adapt Strateg Glob Change 12:495-524

Füssel HM (2007) Vulnerability: a generally applicable conceptual framework for climate change research. Glob Environ Change 17:155-167

Holman IP, Rounsevell MDA, Cojacaru G, Shackley S and others (2008) The concepts and development of a participatory regional assessment tool. Clim Change 90:5-30

IPCC (2007) Climate change 2007: the physical science basis. Summary for policy makers. Contribution of Working Group I to the Fourth Assessment Report of the Intergovernmental Panel on Climate Change (www.ipcc.ch/pdf/ assessment-report/ar4/wg1/ar4-wg1-spm.pdf)

Kelly PM, Adger NW (2000) Theory and practice in assessing vulnerability to climate change and facilitating adaptation. Clim Change 47:325-352

Larrivée C, Simonet G (2008) Using climate scenarios at municipal scale. In: Gardner SM, Noble D (eds) Stepping up to the climate change challenge: perspectives on local government leadership, policy and practice in Canada. Municipal World, Ontario

Lemmen DS, Warren FJ, Lacroix J, Bush E (eds) (2008) From impacts to adaptation: Canada in a changing climate 2007. Government of Canada, Ottawa (http://adaptation2007. nrcan.gc.ca)

Mehdi BC, Mrena C, Douglas A (2005). Adapting to climate change: an introduction for Canadian municipalities. CCIARN, Montréal

Niemeijer D, de Groot RS (2008) Framing environmental indicators: moving from causal chains to causal networks. Environ Dev Sustain 10:89-106
NOAA Coastal Services Center (1999) Vulnerability assessment tutorial (www.csc.noaa.gov/products/nchaz/startup. $\mathrm{htm}$, accessed in 2004)

OECD (1993) OECD core set of indicators for environmental performance reviews. OECD Environment Monographs No. 83, OECD, Paris (http://lead.virtualcentre.org/en/dec /toolbox/Refer/gd93179.pdf)

OECD (2006) Metrics for assessing the economic benefits of climate change policies: sea level rise. ENV/EPOC/ GSP(2006)3/FINAL, OECD， Paris (www.nssd.net/pdf/ gd93179.pdf)

Ouranos (2004) S'adapter aux changements climatiques, Montréal (www.ouranos.ca/doc/produit_f.html, accessed 16 March 2006)

Plummer DA, Caya D, Frigon A, Côté H and others (2006) Climate and climate change over North America as simulated by the Canadian RCM. J Clim 19:3112-3132

Savard JP, Bourque A (2008). Adapter les zones côtières aux changements climatiques: de la consultation à l'action. Actes Coll Xèmes Journées Natl Génie Côtier - Génie Civil, 14-16 octobre 2008, Sophia-Antipolis, p 487-501

Savard JP, Bernatchez P, Morneau F, Saucier F and others (2008). Étude de la sensibilité des côtes et de la vulnérabilité des communautés du golfe du Saint-Laurent aux impacts des changements climatiques: synthèse des résultats. Ouranos, Montreal

Schiegg O (2000) DRM strategy, tactics, example. World Institutes for Disaster-Risk-Management (www.drmonline. net/drmlibrary/pdfs/DRMStrategy.pdf)

Senneville S, Saucier FJ (2007). Étude de sensibilité de la glace de mer au réchauffement climatique dans le golfe et l'estuaire du Saint-Laurent. Rapport préparé pour Ouranos et soumis le 30 octobre 2006.

Tecsult (2008) Analyse coûts-avantages de solutions d'adaptation à l'érosion côtière pour la Ville de Sept-îles. Internal report (May 2008), Tecsult, Montreal

United Nations Division for Sustainable Development (2008) Measuring progress towards sustainable development and climate change - the potential of the CSD indicators of sustainable development. Background paper, Expert Group Meet Clim Change Sustain Dev: -'The role of indicators', New York, 15-16 October 2008. UNDP

> Vescovi L, Rebetez M, Rong F (2005) Assessing public health risk due to extremely high temperature events: climate and social parameters. Clim Res 30:71-78

> Vincent LA (1998) A technique for the identification of inhomogeneities in Canadian temperature series. J Clim 11:1094-1104

Vincent LA and Mekis É (2006) Changes in daily and extreme temperature and precipitation indices for Canada over the twentieth century. Atmos-Ocean 44(2):177-193

$\mathrm{Xu}$ Z, Saucier FJ, Lefaivre D (2006) Water level variations in the Estuary and Gulf of St. Lawrence. Presentation at the 'Understanding sea-level rise and variability' Workshop, June 6-9, 2006, Paris (http://wcrp.ipsl.jussieu.fr/Workshops/SeaLevel/Posters/2_13_Xu.pdf)

Yagouti A, Boulet G, Vincent L, Vescovi L, Mekis E (2008) Observed changes in daily temperature and precipitation indices for Southern Québec, 1960-2005. Atmos-Ocean 46:243-256

Yohe G (2000) Assessing the role of adaptation in evaluating vulnerability to climate change. Clim Change 46:371-390

Proofs received from author(s): August 27, 2009 